\title{
Desempenho operatório de crianças com queixas de desatenção e hiperatividade em jogos eletrônicos baseados em provas Piagetianas
}

\author{
Operating performance of children with symptoms \\ of inattention and hyperactivity in electronic \\ games based on Piagetian tasks
}

\author{
Claudia Broetto ROSSETTI ${ }^{1}$ \\ Maria Thereza Costa Coelho de SOUZA ${ }^{2}$ \\ Fabíola RÖHRIG ${ }^{1}$ \\ Queila Cássia Corrêa GUIMARÃES ${ }^{1}$ \\ Simone Chabudee PYLRO ${ }^{1}$ \\ Taisa Rodrigues Smarssaro BAHIENSE ${ }^{1}$
}

\begin{abstract}
Resumo
Realizou-se uma avaliação operatória em contexto virtual de 16 crianças entre sete e 10 anos com queixas de desatenção e hiperatividade por meio dos jogos eletrônicos "Zona Trash 3" e "Protocolos", construídos a partir de provas Piagetianas clássicas. Solicitou-se às pedagogas de uma escola pública que indicassem crianças com indícios de dificuldades de atenção e/ou hiperatividade. Os professores das crianças indicadas responderam à Escala de Transtorno de Déficit de Atenção e Hiperatividade, e foram incluídas como participantes da pesquisa apenas as crianças que obtiveram os maiores escores na referida escala. Quase a totalidade dos participantes conseguiu chegar ao final dos dois jogos. Observou-se maior dificuldade no jogo "Protocolos", que avalia a lógica combinatória e que, em geral, exige maior paciência e concentração dos participantes. Dessa maneira, os jogos de regras eletrônicos "Protocolos" e "Zona Trash 3" apresentam-se como bons instrumentos para a avaliação das noções operatórias de lógica combinatória e raciocínio espacial em crianças que apresentam indícios de transtorno de déficit de atenção e hiperatividade.
\end{abstract}

Palavras-chave: Desenvolvimento infantil; Jogos de vídeos; Tarefas Piagetiana; Transtorno de déficit de atenção e hiperatividade.

vrv

1 Universidade Federal do Espírito Santo, Departamento de Psicologia Social e do Desenvolvimento, Programa de Pós-Graduação em Psicologia. Av. Fernando Ferrari, 514, Goiabeiras, 29075-910, Vitória, ES, Brasil. Correspondência para/Correspondence to: C.B. ROSSETTI. E-mail: <cbroetto.ufes@gmail.com>.

${ }^{2}$ Universidade de São Paulo, Instituto de Psicologia, Laboratório de Estudos sobre Desenvolvimento e Aprendizagem. São Paulo, SP, Brasil.

O artigo foi elaborado a partir da tese de C.B. ROSSETTI, intitulada "Avaliação de noções operatórias em contextos concretos e virtuais: um estudo com crianças com e sem indícios de dificuldades de atenção". Universidade de São Paulo, 2011.

Apoio: À Fundação de Amparo à Pesquisa do Espírito Santo (Processo no 45432767/2009) e ao Conselho Nacional de Desenvolvimento Científico e Tecnológico (Processo no 150326/2010-6). 


\begin{abstract}
An operative evaluation was conducted in the virtual context of 16 children between seven and 10 years with inattention and hyperactivity symptoms by means of the electronic games "Trash Zone 3" and "Protocols", constructed from classic Piagetian tasks. Educators of a public school were asked to indicate children with signs of attention difficulties and/or hyperactivity. The teachers of these children responded to the Attention Deficit Disorder with Hyperactivity Scale and only the children who obtained the highest scores in this scale were included as participants in this study. Almost all participants made it to the final in the two games. This was more difficult in the "Protocols" game, which evaluates the combinational logic and, in general, requires more patience and concentration from participants. Thus, the electronic games of rules "Protocols" and "Trash Zone 3" were good instruments for the assessment of operative notions of combinational logic and spatial reasoning in children who exhibit signs of Attention Deficit Disorder with Hyperactivity.
\end{abstract}

Keywords: Childhood development; Video games; Piagetian tasks; Attention deficit disorder with hyperactivity.

Segundo Piaget e Inhelder (1966/2002), o desenvolvimento humano deve ser compreendido como um processo de equilibração progressiva, ou seja, como a passagem de estágios de menor equilíbrio para outros de maior equilíbrio cognitivo. De acordo com os mesmos autores, essas sucessivas construções seguem uma ordem constante, ainda que o ritmo seja sempre variável de indivíduo para indivíduo.

Para os referidos autores, existem quatro aspectos fundamentais que estão sempre presentes no processo de desenvolvimento: a maturação do sistema nervoso, que é condição necessária, mas não suficiente, para o comparecimento de novas condutas; a experiência ativa, que possibilita ao sujeito a ação sobre os objetos, seja na perspectiva da experiência física (abstração das propriedades físicas dos objetos), seja na da experiência lógico-matemática (abstração das ações sobre os objetos e eventos); as interações sociais, que envolvem aspectos de socialização que supõem instrumentos operatórios cognitivos e afetivos; e a equilibração propriamente dita, que é o fator organizador dos outros já mencionados e o regulador do desenvolvimento em geral (Piaget \& Inhelder, 1966/2002). Desse modo, para Piaget (1971/2002), o desenvolvimento cognitivo ocorre a partir das ações mais elementares do recém-nascido, organizando-se em estágios que se sucedem ao longo da vida em um processo contínuo de construção: inteligência sensório-motora, inteligência pré-operatória e inteligência operatória (concreta e formal).

Piaget, ao longo de sua extensa obra, propôs 378 uma série de exames, conhecidos como provas
Piagetianas, que têm o objetivo de investigar o pensamento infantil por meio do método clínico, também proposto por ele (Delval, 2002). Particularmente no que se refere à passagem do pensamento pré-operatório (pré-lógico) para o pensamento operatório (lógico), foram propostas uma série de situações, muitas delas com material lúdico para avaliar as mais diversas noções operatórias, ou seja, o que não é possível para a criança no período pré-operatório e passa a ser a partir do período operatório concreto (Carraher, 1989; Correa, 1991).

É importante salientar que Piaget sempre esteve interessado em entender como ocorre o desenvolvimento típico. No entanto, outros autores têm proposto pesquisas com as provas Piagetianas (ou situações experimentais baseadas nas provas operatórias) também para a análise do pensamento de crianças que supostamente estejam apresentando alguma dificuldade ligada aos processos de desenvolvimento e/ou aprendizagem (Brown, Borden, Schleser, Clingerman, \& Orenczuk, 1985; Campos, Goldberg, Capellini, \& Padula, 2007; Folquitto, 2009).

\section{Dificuldades de atenção: dúvidas e questões atuais}

Segundo Legnani e Almeida (2008), as primeiras descrições médicas sobre as dificuldades de atenção remontam ao início do século 20. Trata-se de um tema bastante atual e, devido ao seu caráter de aparente prevalência cada vez maior, tem 
sido objeto de estudo de profissionais das mais diversas áreas. De fato, segundo dados da American Psychiatric Association (APA), estima-se que os transtornos de atenção ocorram em 3 a $6 \%$ da população mundial em idade escolar (Graeff \& Vaz, 2008).

Para fins de diagnóstico, os sintomas do Transtorno de Déficit de Atenção e Hiperatividade (TDAH) devem gerar comprometimento significativo em pelo menos dois contextos diferentes da vida, além de não serem mais bem explicados por outro transtorno mental (APA, 2003). Esse comprometimento deve ser sempre avaliado a partir das potencialidades do indivíduo e do grau de esforço necessário para a manutenção do ajustamento. Além disso, exige não somente que a criança seja examinada, mas também que seja realizada entrevista com os pais, além de obtenção de informações com a escola (Coutinho, Mattos, Araujo, \& Duchesne, 2007).

Dentre os sintomas usualmente presentes no TDAH, os que mais se destacam são os que compõem a tríade clássica da síndrome: desatenção, hiperatividade e impulsividade. A desatenção configura-se como dificuldade para sustentar a atenção por períodos prolongados ou errar por descuido em atividades escolares e de trabalho, seguir instruções, completar as lições e organizar tarefas; tendência a perder objetos, esquecer compromissos e distrair-se com estímulos externos; parecer não escutar quando lhe dirigem a palavra; relutar ou evitar envolver-se em tarefas que exijam esforço mental constante. A hiperatividade se caracteriza pela agitação motora, inquietude e tendência a falar excessivamente; dificuldade em brincar ou envolver-se silenciosamente em atividades de lazer. Já a impulsividade se configura como dificuldade de aguardar sua vez e tendência de interromper os outros ou intrometer-se em assuntos alheios (Landskron \& Sperb, 2008; Rohde, Barbosa, Tramontina, Polanczyk, 2000).

O Diagnostic and Statistical Manual of Mental Disorders - IV - Text Revision (DSM-IV-TR, Manual Diagnóstico e Estatístico de Transtornos Mentais - IV - Texto Revisado), (APA, 2003) categoriza os pacientes em três grupos distintos: TDAH tipo combinado, TDAH tipo predominantemente desatento e TDAH tipo predominantemente hiperativo. A prevalência desse transtorno na população infantil é estimada em 4,5\% a 9,0\% para o subtipo desatento, $1,7 \%$ a 3,9\% para o subtipo hi-perativo e impulsivo, e de 1,9\% a 4,8\% para o subtipo combinado (Grevet, Abreu, \& Shansis, 2003). O tipo com predomínio de sintomas de desatenção é mais frequente no sexo feminino e parece apresentar, conjuntamente com o tipo combinado, uma taxa mais elevada de prejuízo acadêmico.

Rohde e Halpern (2004) afirmam que algumas pistas podem indicar a presença do transtorno, tais como a duração dos sintomas de desatenção e/ou de hiperatividade/impulsividade, a frequência e a intensidade dos sintomas, a persistência dos sintomas em vários locais e ao longo do tempo, o prejuízo clinicamente significativo na vida da criança. A transformação das dificuldades de atenção em transtorno ou déficit acaba tendo uma série de implicações para todos que lidam de alguma forma com o tema. A mais importante delas talvez seja a naturalização da dificuldade de atenção, aliada à abordagem cada vez mais medicamentosa da questão (Caliman, 2010).

Dessa maneira, no que se refere ao processo de avaliação do transtorno, observam-se diferenças marcantes no que diz respeito à nomenclatura empregada e aos critérios de diagnóstico. Assim, têm-se, por exemplo, as descrições apresentadas pela Classificação Internacional de Doenças (CID-10) e pelo DSM-IV-TR, que, segundo Folquitto (2009), não são exatamente correspondentes, pois se verificam diferenças marcantes relativas aos critérios de diagnóstico apresentados nos dois manuais.

A intervenção, por sua vez, também se apresenta como um grande desafio nos casos de dificuldades de atenção, pois nem sempre é possível contar com a estrutura multidisciplinar que seria necessária para atender corretamente as crianças que apresentam indícios de tal problemática e suas respectivas famílias. A partir de tais desafios, colocam-se como necessárias novas abordagens sobre o assunto a fim de se chegar a intervenções mais eficazes no que diz respeito às dificuldades de atenção. Nesse sentido, destacam-se as discussões 
apresentadas nos trabalhos de Folquitto (2009) e Missawa e Rossetti (2008), que, além de contribuírem para a avaliação desse transtorno, propõem inovações nas possibilidades de intervenção nas dificuldades de atenção a partir de explicações pautadas na Epistemologia Genética de Jean Piaget, o que vai ao encontro da proposta da presente pesquisa.

Em sua dissertação de Mestrado, Folquitto (2009) verificou que crianças diagnosticadas com TDAH apresentaram atrasos significativos em alguns domínios específicos na aquisição de noções operatórias de pensamento, em especial as noções de número, de tempo, de conservação e de reversibilidade. Também se evidenciou na referida pesquisa a carência de estudos que investiguem se o déficit operatório apresentado leva a dificuldades que comprometem o pensamento lógico de maneira global ou se "existiriam domínios e noções específicas que estariam prejudicadas somente em crianças hiperativas, relacionando-se com os sintomas apresentados" (Folquitto, 2009, p.105).

Por sua vez, Missawa e Rossetti (2008) utilizaram o jogo de regras Mancala ${ }^{3}$ como instrumento de ampliação da compreensão das dificuldades de atenção em crianças com TDAH. As discussões realizadas pelas referidas autoras indicam que apesar de as crianças com TDAH terem apresentado mais condutas de desatenção durante a prática do referido jogo, não existe uma diferença radical entre o desempenho global dos indivíduos que, teoricamente, apresentam tais dificuldades e o daqueles que não as apresentam. Portanto, parece ser relevante que se busquem novos instrumentos para o diagnóstico e para a intervenção com crianças com dificuldades de atenção, a fim de se ter uma visão ampliada da questão.

Considerando-se os entraves relatados acima para a realização do diagnóstico e as muitas incertezas que ainda pairam sobre as melhores formas de intervenção no que diz respeito às dificuldades de atenção, optou-se, na presente pesquisa, por fazer menção apenas a possíveis indícios de dificuldades de atenção, sem intenção de propor diagnósticos fechados.

\section{Contextos virtuais, jogos de regras e teoria piagetiana}

Os jogos de regras aparecem em diversos momentos da extensa obra de Jean Piaget. De fato, desde as célebres partidas de bolinhas de gude jogadas com meninos das escolas de Genebra, que deram origem ao importante capítulo sobre a gênese da noção de regras publicado em "O juízo moral na criança" (Piaget, 1932/1994), passando pelo tradicional capítulo sobre as diferentes estruturas de jogo, publicado em "A formação do símbolo na criança" (Piaget, 1946/1971), chega-se a inúmeros outros momentos em que os mais variados jogos e situações lúdicas foram utilizados pelo autor suíço e seus colaboradores como instrumentos de avaliação dos mais diversos processos cognitivos. No Brasil, desde o início das atividades do Laboratório de Psicopedagogia da Universidade de São Paulo (LAPp-USP), na década de 1980, inúmeras pesquisas têm sido realizadas com jogos de regras como instrumento de avaliação e intervenção dos processos cognitivos (Macedo, 2009).

A ideia do uso das novas tecnologias para a análise dos processos cognitivos não é recente e remonta à época da ascensão do computador ao status de ferramenta de uso pessoal, na década de 1980. O norte-americano Seymour Papert, nascido na África do Sul, foi pioneiro no uso do computador na educação. Baseado nas ideias de Piaget sobre a construção do conhecimento, Papert criou a linguagem Logo, que pode ser usada por crianças a partir de seis anos para programar e desenhar figuras matemáticas no computador (Papert, 1980). Desde então, os avanços observados na área de informática provocaram aumento sensível da utilização do computador, sobretudo na área de educação, bem como uma evolução na metodologia relacionada ao seu uso.

\section{$\boldsymbol{\nabla} \boldsymbol{\nabla} \boldsymbol{\nabla}$}

${ }^{3}$ Família de jogos africanos disputados em um tabuleiro com várias concavidades e com o mesmo princípio de distribuição de peças, intimamente associado à semeadura. Este fato, aliado ao local de origem, leva alguns estudiosos a crer que se trate da família de jogos 
Em relação especificamente ao uso de ambientes virtuais para a avaliação de noções operatórias, a revisão de literatura mostra algumas tentativas de transformar determinadas provas Piagetianas clássicas em softwares ou jogos eletrônicos (Andersson, Richards, \& Hallahan, 1980; Quaiser-Pohl, Gêiser, \& Lehmann, 2006). No entanto, observa-se que, na maior parte das vezes, tais empreitadas resultam em atividades ou tarefas que acabam por se afastar do aporte epistemológico que embasa a teoria Piagetiana. Portanto, parece ser de suma importância que se busquem novos instrumentos para o diagnóstico assim como para a intervenção com crianças com TDAH, de maneira a possibilitar a construção de uma visão ampliada das dificuldades de atenção. Dessa maneira, o objetivo da presente pesquisa foi investigar a viabilidade da utilização de jogos eletrônicos baseados em provas Piagetianas como instrumentos de avaliação das noções operatórias de raciocínio espacial e de lógica combinatória em crianças que apresentam indícios de TDAH.

\section{Método}

\section{Participantes}

Participaram da pesquisa 16 crianças na faixa etária de 7 a 10 anos, que apresentavam sintomas de desatenção e hiperatividade, e eram alunos do ensino fundamental de uma escola pública municipal de Vitória, Espírito Santo, Brasil.

\section{Instrumentos e Procedimentos}

Após a aprovação do presente projeto pelo Comitê de Ética em Pesquisa local (CEP-Universidade Federal do Espírito Santo), a fim de se fazer a seleção dos participantes, solicitou-se aos professores das crianças previamente indicadas pelas pedagogas da escola como portadoras de comportamentos característicos do transtorno que respondessem à Escala de TDAH - versão para professores (Benczik, 2000), que tem por objetivo inferir indícios de dificuldades de atenção no contexto escolar a partir de informações apresentadas pelos professores. Trata-se da única escala atualmente reconhecida pelo Conselho Federal de Psicologia (CFP) como instrumento para avaliação do referido transtorno por psicólogos no Brasil; segundo a autora, sua elaboração levou em consideração os diversos fatores socioculturais e sociodemográficos característicos do país (Benczik, 2000). A escala é do tipo Likert de seis pontos, apresenta 49 itens organizados em positivos (indícios de TDAH) e negativos (sem indícios de TDAH) e avalia quatro fatores: déficit de atenção, problemas de aprendizagem, hiperatividade/impulsividade e comportamento antissocial. A referida escala foi res-pondida individualmente e os alunos que atingiram um percentil acima de 75 em pelo menos dois dos fatores avaliados foram convidados a participar das etapas seguintes da pesquisa. Em um segundo momento, foram aplicadas as provas computadorizadas, juntamente com as entrevistas.

Antes do início da pesquisa, foi necessário que a diretora da escola assinasse um documento permitindo sua realização. Além disso, cada professor que preencheu a supracitada escala assinou um Termo de Consentimento Livre e Esclarecido (TCLE). Em seguida, uma carta foi enviada aos pais das crianças pré-selecionadas, juntamente com um TCLE, solicitando o consentimento para a participação de seus filhos na pesquisa. A coleta de dados ocorreu nas dependências da escola, em um ambiente que pouco interferisse na realização das atividades, durante o semestre letivo, em horários combinados com as professoras e coordenadoras da escola; em cada encontro, estavam sempre presentes duas pesquisadoras.

Para a avaliação operatória das noções de raciocínio espacial e de lógica combinatória, foram utilizados dois jogos eletrônicos de regras que fazem parte do software Mission Cognition (Missão Cognição), elaborado na Suíça por Haddad-Zubel, Pinkas e Pecault (2004) e traduzido para o português pela professora Luisa Morgado da Universidade de Coimbra ${ }^{4}$. A tela de abertura desse software

\footnotetext{
$\boldsymbol{\nabla} \nabla \boldsymbol{\nabla}$

${ }^{4}$ A utilização do referido software na presente pesquisa foi autorizada pela Profa. Rosita Haddad-Zubel durante um intercâmbio acadêmico no Brasil no ano de 2008 .
} 
apresenta uma galáxia com nove peculiares planetas, cada qual constituindo um jogo eletrônico elaborado com base em provas operatórias de Piaget. Ao clicar sobre cada planeta, um diferente jogo se inicia.

O primeiro jogo utilizado, chamado "Protocolos", é baseado na prova piagetiana clássica sobre lógica combinatória proposta no livro " $A$ origem da idéia de acaso na criança" (Piaget \& Inhelder, 1951/n.d.). Esse jogo permite avaliar o desempenho de ações que demandem as operações de combinação. Na prática desse jogo, explica-se à criança que o planeta Protocolos precisa remover seus habitantes em naves espaciais, sendo que cada nave só comporta dois habitantes, diferentes ou iguais, não importando a sequência em que os habitantes embarcam. Assim, pede-se à criança que faça o maior número de combinações diferentes de dois habitantes para que as naves possam partir. O jogo apresenta quatro fases: na primeira, são apresentados dois tipos de habitantes, e aumenta-se um tipo a cada fase, até que haja cinco tipos de habitantes para serem combinados dois a dois. $O$ jogo só finaliza quando são feitas todas as combinações possíveis de habitantes.

O segundo jogo utilizado, "Zona Trash 3", é baseado na prova clássica piagetiana das "Três Montanhas", que pode ser encontrada no livro " $A$ representação do espaço na criança" (Piaget \& Inhelder, 1948/1993), e avalia o raciocínio espacial. O jogo simula um planeta contaminado por radiação

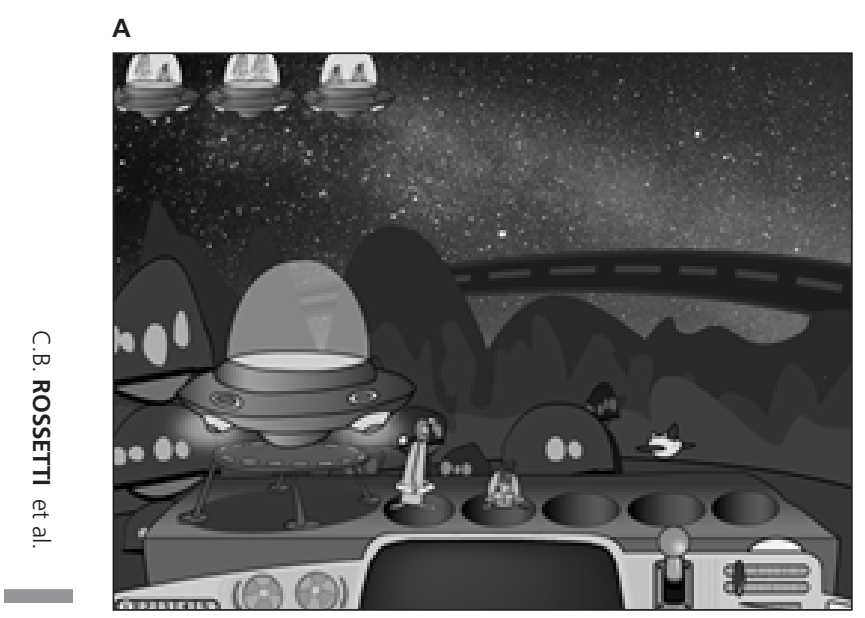

382

Figura 1. Telas de abertura dos jogos "Protocolos" e "Zona Trash 3". onde apenas um pequeno avião dotado de câmera fotográfica pode chegar. O jogador guia o avião, que tem o objetivo de tirar fotos idênticas às apresentadas no canto esquerdo da tela. Na fase seguinte, há uma tempestade de areia que dificulta a realização da tarefa; em cada fase, cinco fotos devem ser tiradas. As telas de abertura dos dois jogos utilizados na presente pesquisa encontram-se na Figura 1.

Assim, foram jogadas quatro partidas: duas do jogo "Protocolos" e duas do jogo "Zona Trash 3" com cada criança. Nas primeiras partidas de cada jogo, explicavam-se as regras e o participante podia jogar com o auxílio da pesquisadora, tirando dúvidas e fazendo perguntas. Durante as segundas partidas, o participante devia jogar sem nenhum tipo de auxílio: somente essas segundas partidas foram analisadas.

Antes do início da prática dos jogos, foi realizada uma entrevista semiestruturada com questões que objetivavam verificar a familiaridade dos participantes com computadores e jogos eletrônicos, bem como identificar os jogos preferidos dos participantes e o local onde eles eram praticados. Ao final da segunda partida de cada jogo, foi realizada ainda outra entrevista semiestruturada, na qual se perguntava a cada criança se havia gostado do jogo e o que tinha pensado enquanto jogava (suas estratégias etc.). Para a realização das entrevistas, utilizou-se o método clínico Piagetiano (Carraher, 1989; Delval, 2002; Piaget, 1947/2005).

B

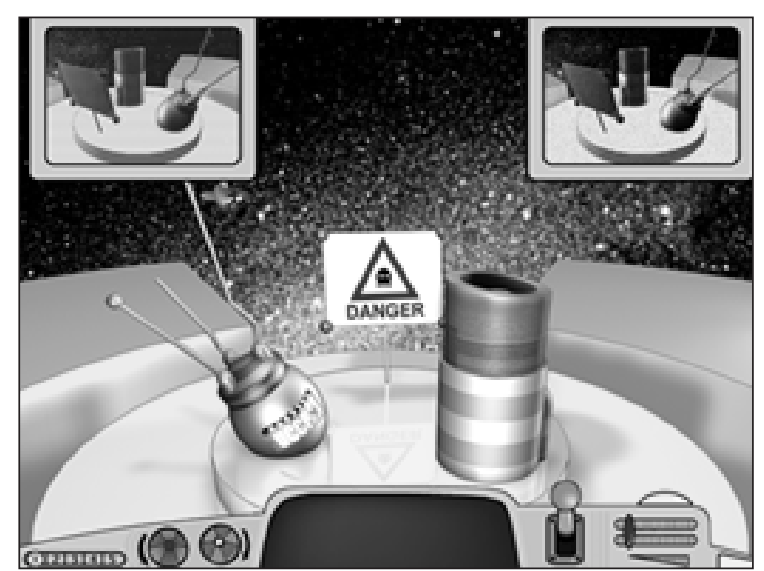


As verbalizações das crianças durante os jogos, bem como as entrevistas, foram gravadas em áudio digital e posteriormente transcritas. Foram realizadas, também, anotações em um diário de campo mantido pelas pesquisadoras. Durante a prática dos jogos no computador, eram geradas automaticamente pelo software planilhas em Excel $^{\circledR}$ que registram todas as ações realizadas pelas crianças durante cada partida, o que permite a análise posterior do desempenho de cada criança.

\section{Resultados}

No que diz respeito ao sexo dos participantes, houve grande prevalência masculina na amostra - 14 meninos e apenas 2 meninas -, o que corrobora outras pesquisas relacionadas à temática do TDAH, que indicam que há uma maior incidência de diagnóstico do transtorno no sexo masculino (Poeta \& Rosa Neto, 2004; Fontana, Vasconcelos, Werner, Góes, \& Liberal, 2007).

Considerando que neste estudo as provas Piagetianas foram apresentadas em formato de jogo eletrônico, julgou-se apropriado verificar se os participantes tinham alguma familiaridade com jogos eletrônicos, e se utilizavam o computador como recurso para jogar. Assim, verificou-se que 93,7\% da amostra gostavam de jogar tal modalidade de jogos e que, destes, 81,2\% afirmaram jogar frequentemente. No que diz respeito ao local onde costumam jogar, a própria casa $(50,0 \%)$ e a casa de algum familiar $(37,5 \%)$ foram os locais mais citados.

Para o jogo "Protocolos", os participantes conseguiram concluir as partidas em uma média de 6,31 minutos. A partida mais longa teve a duração de 17,11 minutos e a mais curta durou 1,34 minutos. Do total de partidas analisadas do referido jogo, 75\% continham erros de repetição de combinação; a ocorrência desse tipo de erro ficou assim distribuída: cinco erros na fase I, 7 erros na fase II, 23 erros na fase III e 31 erros na fase IV do jogo.

No caso do jogo eletrônico "Protocolos", não há a possibilidade de se analisarem os tipos de erros cometidos, mas apenas a quantidade deles, em cada um dos quatro níveis do jogo. Percebe-se que, à medida que as fases mais difíceis do jogo vão surgindo, o número de erros vai aumentando. Tal fato era esperado, tendo em vista a faixa etária dos participantes (entre 7 e 10 anos), para a qual é esperado que a noção de lógica combinatória, que constitui a essência do jogo, esteja em processo de construção (Piaget \& Inhelder, 1951/n.d.).

Após as duas partidas do jogo "Protocolos", foi feita uma pequena entrevista na qual era perguntado aos participantes sobre quais estratégias usaram para conseguir chegar ao final do jogo. As respostas foram muito diversas, tais como: "conferir as combinações já formadas" (31,25\%) e "relembrar a partida de treino" (18,75\%). Buscou-se categorizar tais respostas como "estratégias corretas" - que continham elementos importantes para se obter sucesso no jogo e "estratégias incorretas" -, aquelas que eram vagas ou que não continham nenhuma conexão com um possível bom desempenho no jogo. Além disso, separaram-se em uma categoria as respostas que eram apenas uma opinião sobre o jogo, como "legal" ou "difícil" (Tabela 1).

Perguntou-se também sobre qual dica cada participante daria a outra criança que fosse jogar o mesmo jogo. As categorias de respostas mais encontradas foram "pensar/prestar atenção" (31,25\%) e "conferir as combinações no momento de realizá-las" (18,75\%).

Para o jogo "Zona Trash 3", cada partida durou em média 3,45 minutos: a partida mais longa teve a duração de 6,27 minutos, e a mais curta, 2,18 minutos. Dos 54 erros cometidos pelos participantes, 7 (12,96\%) ocorreram na primeira fase do jogo, e 47 (87,03\%), na segunda, que apresentava um maior grau de dificuldade. Do total de erros cometidos, $42(77,77 \%)$ eram dos tipos 1 e 2 (afastamento de $45^{\circ}$ e $90^{\circ}$ da posição correta respectivamente), considerados erros mais brandos. O erro mais grave, do tipo 4 (afastamento de $180^{\circ}$ da posição correta), apareceu apenas 8 vezes $(14,81 \%)$, conforme apresentado no Figura 2.

Quando se perguntou aos participantes sobre quais estratégias usaram para conseguir chegar ao final desse jogo, as categorias de respostas mais 
Tabela 1

Estratégias mais utilizadas durante a prática do jogo "Protocolos"

\begin{tabular}{lcc}
\hline Estratégias & Frequência & Porcentagem \\
\hline Corretas & 9 & 56,2 \\
Incorretas & 6 & 37,5 \\
"Legal/Difícil" & - & - \\
Nada/Não sabia & 1 & 6,3 \\
\hline Total & 16 & 100,0 \\
\hline
\end{tabular}

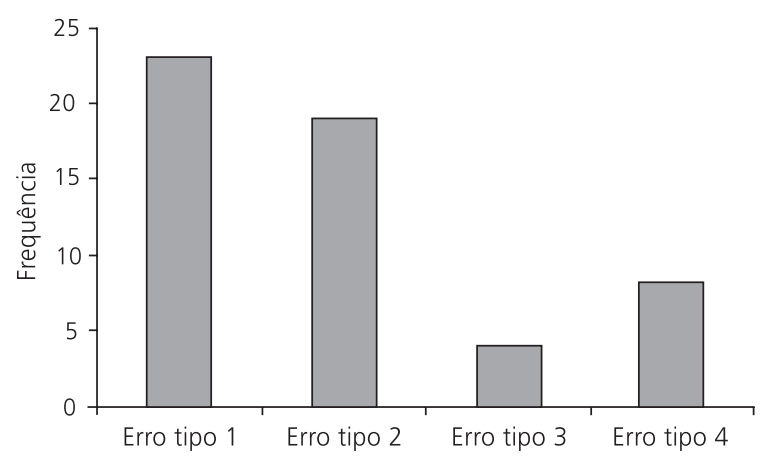

Figura 2. Distribuição dos tipos de erros durante a prática do jogo "Zona Trash 3".

Nota: Erro tipo 1: afastamento de $45^{\circ}$ da posição correta; Erro tipo 2: afastamento de $90^{\circ}$ da posição correta; Erro tipo 3: afastamento de $135^{\circ}$ da posição correta; Erro tipo 4: afastamento de $180^{\circ}$ da posição correta.

comuns foram "lembrar-se da fase anterior" $(12,5 \%)$ e "observar bem a foto apresentada" $(18,75 \%)$. Em relação à pergunta "Se você tivesse que dar uma dica para outra criança que vai jogar, o que você diria?", as categorias de respostas mais encontradas foram "prestar atenção na posição da câmera" (18,75\%), "imaginar-se dentro do turbo" (6,25\%) e "manter a atenção na tela" (6,25\%).

Assim, de maneira geral, observou-se que grande parte das crianças apresentou dificuldade para descrever as estratégias utilizadas em ambos os jogos. Apesar disso, entre as que conseguiram explicitar tais estratégias, foi possível constatar uma coerência com as regras e os objetivos dos jogos. No decorrer da coleta, observou-se ainda que 10 das 16 crianças externaram, por meio da fala, pensamentos e estratégias relacionados à prática dos jogos, como, por exemplo: "O rosa com o azul, o rosa com amarelo" (referindo-se às combinações de cores dos habitantes do planeta Protocolos).
Além dessas, também ocorreram verbalizações que não indicavam relação direta com as regras dos jogos, como: "Saturno é o rei dos anéis, todo mundo diz" (durante a prática do jogo "Zona Trash 3").

\section{Discussão}

A análise dos resultados indicou que cerca de metade $(n=8)$ dos participantes ainda não concluiu o processo de construção das noções de lógica combinatória e raciocínio espacial. De fato, durante as partidas do jogo "Protocolos", por vezes esqueciam as combinações que já haviam realizado nas fases anteriores, parecendo partir do zero a cada nova fase. No jogo "Zona Trash 3", por vezes não conseguiam se descentrar espacialmente o suficiente para tirarem as fotos sem a ajuda da imagem que a câmera da nave mostrava.

No que diz respeito à variável idade, observou-se que o desempenho dos participantes mais velhos foi, em média, ligeiramente melhor do que o dos participantes mais novos. Contudo, todos os participantes conseguiram chegar ao final das partidas de ambos os jogos, apresentando um desempenho dentro do esperado para a faixa etária investigada, de acordo com o que propõe a teoria piagetiana. A estrutura do jogo, que apresenta níveis mais complexos à medida que a partida avança, e os feedbacks gerados pelo próprio software pareceram repercutir de forma positiva no desempenho do conjunto dos participantes.

De maneira geral, os resultados indicaram que os jogos de regras eletrônicos "Protocolos" e "Zona Trash 3" apresentam-se como bons instrumentos para a avaliação das noções operatórias da lógica combinatória e do raciocínio espacial em crianças que apresentam indícios de TDAH. O desempenho dos participantes, considerando-se o que se espera para a faixa etária em que se encontram, parece indicar que as noções avaliadas não se mostraram afetadas de maneira significativa nos participantes da amostra com indícios de desatenção e hiperatividade do presente estudo. Tais dados parecem ir ao encontro da literatura revisada, que vem mostrando de maneira cada vez mais contundente que a desatenção e a hiperatividade 
não podem ser confundidas com falta de inteligência ou de raciocínio (Benczik, 2000; Rohde \& Benczik, 1999; Rohde \& Mattos, 2003).

É importante ressaltar que a alta frequência de comportamentos de agitação durante a prática dos jogos parece não ter interferido no desempenho dos participantes. Tais resultados parecem reforçar a tese de que o formato da atividade, computadorizada e bastante lúdica, favorece muito o acesso ao real potencial de desenvolvimento cognitivo dos participantes, em especial daqueles com indícios de dificuldade de atenção, em relação às noções investigadas.

Assim, parece muito importante salientar mais uma vez a originalidade da proposta do software Mission Cognition (Haddad-Zubel et al., 2005), cujos jogos se baseiam diretamente em provas Piagetianas clássicas e foram cuidadosamente projetados para que todas as situações experienciadas durante sua prática se mantivessem coerentes com a concepção teórica subjacente: a epistemologia genética.

Por fim, espera-se que o presente trabalho possa contribuir para uma melhor compreensão da temática da avaliação operatória em contextos virtuais; para um incremento da utilização de jogos eletrônicos na avaliação do pensamento infantil; e para essa nova abordagem da clássica teoria de desenvolvimento proposta por Jean Piaget.

Além disso, espera-se que os dados advindos da presente pesquisa possam fomentar ainda mais a reflexão sobre a necessidade de se atribuir um peso maior aos aspectos cognitivos do desenvolvimento na infância, bem como possam servir para uma melhor compreensão das causas e efeitos das dificuldades de atenção, ampliando a apresentação de subsídios teóricos e práticos para psicólogos e educadores, sobretudo no que diz respeito à avaliação das noções operatórias por meio da prática de jogos eletrônicos de crianças com indícios de dificuldades de atenção.

\section{Referências}

American Psychiatric Association (2003). Manual Diagnóstico e Estatístico de Transtornos Mentais (DSM-IV-TR). Porto Alegre: Artmed.
Andersson, K. E., Richards, C. H., \& Hallahan, D. P. (1980). Piagetian tasks performance of learning disabled children. Journal of Learning Disabilities, 13(9), 37-41.

Benczik, E. B. P. (2000). Manual da escala de transtorno de déficit de atenção/hiperatividade (versão para professores). São Paulo: Casa do Psicólogo.

Brown, R. T., Borden, K. A., Schleser, R., Clingerman, S. R., \& Orenczuk, S. (1985). The performance of attention deficit disordered and normal children on conservation tasks. The Journal of Genetic Psychology, 146(4), 535-530.

Caliman, L. V. (2010). Notas sobre a história oficial do Transtorno do Déficit de Atenção/hiperatividade TDAH. Psicologia: Ciência e Profissão, 30(1), 45-61.

Campos, L. G. A., Goldberg, T. B. L., Capellini, S. A., \& Padula, N. A. M. R. (2007). Caracterização do desempenho de crianças com Transtorno de Déficit de Atenção e Hiperatividade (TDAH) em provas operatórias: estudos de casos. Revista de Psicopedagogia, 24(75), 218-228.

Carraher, T. N. (1989). O método clínico: usando os exames de Piaget. São Paulo: Cortez Editora.

Correa, J. (1991). O método crítico: o legado metodológico de Piaget ao estudo dos processos cognitivos. Revista de Psicologia e Psicanálise, 3, 53-66.

Coutinho, G.; Mattos, P.; Araújo, C., \& Duchesne, M. (2007). Transtorno do déficit de atenção e hiperatividade: contribuição diagnóstica de avaliação computadorizada de atenção visual. Revista de Psiquiatria Clínica, 34(5), 215-222.

Delval, J. (2002). Introdução à prática do método clínico: descobrindo o pensamento das crianças. Porto Alegre: Artmed.

Folquitto, C. T. F. (2009). Desenvolvimento psicológico e Transtorno de Déficit de Atenção e Hiperatividade (TDAH): a construção do pensamento operatório (Dissertação de mestrado não-publicada). Universidade de São Paulo.

Fontana, R. S., Vasconcelos, M. M., Werner, J., Jr., Góes, F. V., \& Liberal, E. F. (2007). Prevalência de TDAH em quatro escolas públicas brasileiras. Arquivos de Neuro-Psiquiatria, 65(1), 134-137.

Graeff, R. L., \& Vaz, C. E. (2008). Avaliação e diagnóstico do transtorno de déficit de atenção e hiperatividade (TDAH). Psicologia USP, 19(3), 341-361.

Grevet, E. H., Abreu, P. B., \& Shansis, F. (2003). Proposta de uma abordagem psicoeducacional em grupos para pacientes adultos com transtorno de déficit de atenção/hiperatividade. Revista de Psiquiatria, 25(3), 446-452.

Haddad-Zubel, R., Pinkas, D., \& Pecault, S. (2004). Mission Cognition [CD-ROM]. Fribourg: Université de Fribourg.

Landskron, L. M. F., \& Sperb, T. M. (2008). Narrativas de professoras sobre o TDAH: um estudo de caso coletivo. Psicologia Escolar e Educacional, 12(1), 153-167. 
Legnani, V. N., \& Almeida, S. F. C. (2008). A construção diagnóstica de transtorno de déficit de atenção/hiperatividade: uma discussão crítica. Arquivos Brasileiros de Psicologia, 60(1), 02-13.

Macedo, L. (Org.). (2009). Jogos, psicologia e educação. São Paulo: Casa do Psicólogo.

Macedo, L., Petty, A. L., \& Passos, N. C. (2000). Aprender com jogos e situações-problema. Porto Alegre: Artes Médicas.

Missawa, D. D. A., \& Rossetti, C. B. (2008). Desempenho de crianças com e sem dificuldades de atenção no jogo Mancala. Arquivos Brasileiros de Psicologia, 60(2), 60-74.

Papert, S. (1980). Mindstorm: Children, computers, and powerful ideas. New York: Basic Books.

Piaget, J. (1971). A formação do símbolo na criança: imitação, jogo e sonho imagem e representação. Rio de Janeiro: Zahar. (Originalmente publicado em 1946).

Piaget, J. (1994). O juízo moral na criança. São Paulo: Summus. (Originalmente publicado em 1932).

Piaget, J. (2002). Seis estudos de psicologia. Rio de Janeiro: Forense Universitária. (Originalmente publicado em 1964).

Piaget. J. (2005). A representação de mundo na criança: com o concurso de onze colaboradores. Aparecida: Ideias \& Letras. (Originalmente publicado em 1947).

Piaget, J., \& Inhelder, B. (n.d.). A origem da ideia do acaso na criança. Rio de janeiro: Record. (Originalmente publicado em 1951).
Piaget, J., \& Inhelder, B. (1993). A representação do espaço na criança. Porto Alegre: Artmed. (Originalmente publicado em 1948).

Piaget, J., \& Inhelder, B. (2002). A psicologia da criança. Rio de Janeiro: Bertrand Brasil. (Originalmente publicado em 1966).

Poeta, L. S., \& Rosa Neto, F. (2004). Epidemiological study on symptoms of attention deficit/hyperactivity disorder and behavior disorders in public schools of Florianopolis/SC using the EDAH. Revista Brasileira de Psiquiatria, 26(3), 150-155.

Quaiser-Pohl, C., Gêiser, C., \& Lehmann, W. (2006). The relationship between computer-game preference, gender, and mental-rotation hability. Personality and Individual Diferences, 40(3), 609-619.

Rohde, L. A., Barbosa, G., Tramontina, S., \& Polanczyk, G. (2000). Transtorno de déficit de atenção/ hiperatividade. Revista Brasileira Psiquiatria, 22(Supl. 2), 7-11.

Rohde, L. A., \& Benczik, E. B P. (1999). Transtorno déficit de atenção: o que é? Como ajudar? Porto Alegre: Artes Médicas.

Rohde, L. A., \& Halpern, R. (2004). Transtorno de déficit de atenção/hiperatividade: atualização. Jornal de Pediatria, 80(2), S61-S70.

Rhode, L. A., \& Mattos, P. (Orgs.). (2003), Princípios e práticas em TDAH. Porto Alegre: Artmed.

Recebido em: 4/9/2012

Versão final em: 25/3/2013

Aprovado em: 25/4/2013 